\title{
PELATIHAN MANAJEMEN DAYA TARIK WISATA DAN TEKNIK PEMANDUAN WISATA BAGI KELOMPOK TREKKING DI DESA BELOK SIDAN PETANG BADUNG
}

\author{
I.N Sudiarta ${ }^{1}$, N.G.A.S. Dewi ${ }^{2}$, L.G.L.K. Dewi ${ }^{3}$, N.M.S.Wijaya ${ }^{4}$, W.C.J. Sari ${ }^{5}$
}

\begin{abstract}
ABSTRAK
Tujuan kegiatan pengabdian kepada masyarakat adalah memberikan pengetahuan kepada masyarakat desa belok sidan khususnya kelompok sadarwisata dan kelompok trekking "Titi Mamah" tentang bagaimana mengelola daya tarik wisata alam dan teknik pemanduan kegiatan trekking. Pelatihan menggunakan metode ceramah dan diskusi kelompok. Kelompok sadar wisata dan trekking diberikan materi cara mengelola daya tarik wisata berbais kualitas layanan dan kepuasan dan teknik memandu yang memenuhi harapan wisatawan. Hasil kegiatan pelatihan menunjukkan peserta mengikuti pelatihan sangat antusias dan berbagai pertanyaan diajukan terutama berkaitan dengan jenis produk yang dapat dijual dan bagaimana cara memuaskan wisatawan secara berkelanjutan.
\end{abstract}

Kata Kunci: pelatihan, manajemen daya tarik wisata, pemanduan wisata, kelompok trekking.

\begin{abstract}
The purpose of community service activities are to provide knowledge to villagers Belok Sidan particularly Sadar Wisata groups and trekking group "Titi Mamah" about how to manage natural attractions and guiding techniques of trekking activities. The training uses lecture and group discussion. Aware group travel and trekking given materials to manage tourist attraction based on the quality of service and satisfaction and technique guiding that meet the expectations of tourists. The results of training activities show very enthusiastic participants attended training and various questions were raised mainly concerned with the type of products that can be sold and how a satisfactory rating on an ongoing basis.
\end{abstract}

Keywords: community service, tourist attraction management, technique of guiding, trekking group.

\section{PENDAHULUAN}

Daya tarik wisata merupakan salah satu elemen penting yang harus ada pada suatu destinasi pariwisata. Berbagai jenis daya tarik wisata yang ada pada destinasi pariwisata selalu menjadi

1 Staf pengajar program Studi Industri Perjalanan Wisata Universitas Udayana, sudiarta_ipw@unud.ac.id

2 Staf pengajar program Studi Industri Perjalanan Wisata Universitas Udayana, susrami_ipw@unud.ac.id

3 Staf pengajar program Studi Industri Perjalanan Wisata Universitas Udayan, leli_ipw@unud@ac.id

4 Staf pengajar program Studi Industri Perjalanan Wisata Universitas Udayana, sofia_ipw@unud.ac.id

5 Staf pengajar program Studi Industri Perjalanan Wisata Universitas Udayana, dekta.sari@yahoo.com 
Incaran wisatwan untuk dikunjungi, baik oleh wisatawan mancanegara dan nusantara. Bali memiliki daya tarik wisata yang tersebar diseluruh kabupaten dan kota di Bali. Lebih dari 100 daya tarik wisata tersebar di seluruh Bali sehingga memungkinkan wisatawan memiliki banyak pilihan untuk berkunjung.

Jenis daya tarik wisata yang tersedia di Bali meliputi daya tarik wisata budaya, wisata alam dan juga kombinasi dari keduanya. Daya tarik wisata alam merupakan salah salah satu daya tarik utama wisatawan di dunia untuk melakukan perjalanan wisata, disamping daya tarik wisata budaya dan minat khusus atau kombinasi tersebut. Bali memiliki peluang yang signifikan sebagai destinasi pariwisata karena memiliki ketiga potensi tersebut dan dikunjungi wisatawan Mancanegara dan Nusantara (Sudiarta dan Suardana (2016); Sudiarta (2015).

Berbagai strategi yang dilakukan penyedia jasa pariwisata di Bali untuk menarik wisatawan untuk berkunjung dan berkunjung kembali. Salah satunya adalah strategi memuaskan konsumen yang dimulai dari memberikan kualitas pengalaman terbaik kepada wisatawan (Tjiptono dan Gregorius (2011); Foster (2000: 66); Gee et al. (1997).

seperti: kualitas pengalaman di Bandara, di hotel, pada saat penjemputan oleh biro perjalanan wisata, ketika makan dan minum di restoran, pada saat berkunjung pada daya tarik wisata serta membeli cendera mata. Strategi yang dilakukan penyedia daya tarik wisata seperti pengelola trakking hanya terbatas pada menjual produk yang dianggap masih monoton oleh wisatawan. Seperti, hanya menjual satu atau dua jenis paket saja. Padahal wisatawan memerlukan variasi daya tarik wisata yang beragam dan mereka memiliki potensi untuk membelinya.

Tujuan pengabdian ini untuk memberikan pengetahuan bagaimana mengelola daya tarik wisata yang baik dan professional serta bagaimana strategi memandu yang baik sehingga wisatawan puas dan berkonsekuensi pada keinginan untk membeli paket trekking dan memberikan informasi yang positif kepada orang lain. Metode yang digunakan adalah dengan metode ceramah dan praktek langsung dilapangan sehingga peserta yang berjumlah 15 orang tersebut dapat mengerti dan memahami serta mengaplikasikan pengetahuan yang diberikan. Hasil yang diharapkan adalah peserta memiliki pengetahuan mengelola daya tarik wisata dan mengaplikasikan teknik pemanduan wisata yang berkualitas sehingga meningkatkan kepuasan dan keinginan membeli kembali. Peserta dbuatkan brosur, kartu nama, banner serta exbanner sebagai media memasarkan (promosi) desa Belok Sidan sebagai daya tarik wisata kombinasi dari potensi alam dan budaya.

\section{METODE PELAKSANAAN}

Permasalahan masih kurangnya pengetahuan masyarakat dalam mengelola daya tarik wisata diberikan dalam bentuk ceramah dan diskusi. Msayarakat Desa Belok Sidan khususnya Kelompok Sadar Wisata dan Kelompok Trekking diberikan pengetahuan tentang bagaimana cara mengelola daya tarik wisata dengan menggunakan payung konsep Pembangunan Pariwisata Berkelanjutan dan menerapkan konsep pembangunan berbasis masyarakat yang dikenal dengan nama Community Based Tourism. (CBT). Pemecahan masalah kelompok trekking dilakukan dengan memberikan pengetahuan dan praktek tata cara memandu yang dapat memuaskan pelanggan dan menyampaikan semua potensi yang di Desa Belok Sidan Petang Badung.

Konsep pembangunan pariwisata berkelanjutan diberikan agar masyarakat memahami bagaimana cara mengelola dan menjual potensi wisata (baca produk) yang ada di desa Belok Sidan dengan tetap memperhatikan elemen-elemen pelestarian, nilai-nilai sosial budaya dan lingkungan serta manfaat ekonomi yang berkelanjutan. Manfaat pariwisata harus dinikmati oleh semua elemen masyarakat namun tetap memperhatikan pelestarian dan manfaat saat ini dan dimasa mendatang. Dengan konsep pariwisata kerakyatan, masyarakat diharapkan tidak hanya menjadi penonton 
namun sebagai pelaku atau subjek pengembangan pariwisata di desa Belok Sidan. Masyarakat juga diharapkan memiliki data seluruh potensi desa dan melibatkan semua komponen masyarakat mulai dari kepala desa, karang taruna, PKK dan kelompok Sadar Wisata serta kelompok Trekking.

\section{HASIL DAN PEMBAHASAN}

\subsection{Potensi Desa Belok Sidan}

Desa Belok/Sidan adalah nama dari suatu desa yang ada di wilayah kecamatan Petang kabupaten Badung. Secara sepintas dilihat dari namanya terkesan terdiri dari dua nama yaitu Belok dan Sidan. Sejarah desa ini dimulai dari sebuah cerita baha pada jaman dahuklu di Bali terdapat beberapa kerajaan salah satunya adalah kerajaan Pahyangan dan Buleleng. Ketika terjadi peperangan antara kerajaan Pahyangan dan Buleleng, kerajaan Pahyangan mendapat serangan yang hebat dari kerajaaan Buleleng sehingga penduduk dari kerajaaan Pahyangan melarikan diri ke desa Lantang yang merupakan desa yang menjadi lalu lintas antara kerajaan, yang sekarang bernama Selantang yang sekarang menjadi naman salah satu banjar di desa Belok/Sidan.

Kerajaan Pahyangan mengalami kekalahan dan banyak penduduk dari kerajaaan Pahyangan yang mengungsi dari desa Lantang ke suatu tempat yang di beriu nama Kesidan atau Kisidan yang berarti pindahan yang sekarang bernama desa Sidan atau Kesidan. Sampai akhirnya masyarakat membuat pura kahyangan tiga di desa Sidan yang dipindahkan dari perbatasan desa Sidan dan Selantang sehingga kehidupannya semakin aman dan tentram.

Desa Kesidan atau Sidan dahulunya dipimpin oleh dua orang Perbekel, satu dari Perbekel Belok dan atu lagi dari Sidan. Perbekelan Belok terdiri dari lima banjar yaitu banjar Belok, Lawak, Bon Sekarmukti dan Jempanang. Sedangkan Sidan terdiri dari tiga banjar yaitu Sidan, Selantang dan Penikit. Pada tahun 1937 Perbekel Belok adalah Bapak I Wayan Sindhu dan perbekel Sidan dipimpin oleh I Dewa Putu Ceped. Kemudian pada tahun 1957 kedua perbekel dijadikan satu menjadi Desa Belok/Sidan yang dipimpin Bapak I Dewa Putu Ceped. Dan Sejak tahun 1983 tepatnya tanggal 13 Juni Desa Belok/Sidan dipimpin oleh I Wayan Suada Wiyana. Adapun Perbekel Desa Belok Sidan saat ini adalah I Made Rumawan.

\subsection{Pelatihan manajemen daya tarik wisata}

Pelatihan manajemen daya tarik wisata meliputi: 1) bagaimana cara mengetahui potensi yang ada, 2) mengelola dan 3) memasarkan potensi tersebut. Sesungguhnya desa Belok Sidan memiliki potensi alam yang sangat menarik dan masih alami, namun belum digarap dengan serius. Hal ini disebabkan masih kurangnya pemahaman masuyarakat dalam mengelola daya tarik wisata.Belok SIdan juga memiliki potensi sosial dan budaya yang dapat dijadikan daya tarik wisata baik secara terpisah maupun merupakan bagian atau rangkaian produk yang dapat dijual dalam bentuk paket wisata.Potensi desa harus di inventarisasi oleh kelompok sadar wisata beserta dengan komponen masyarakat lainnya seperti karang taruna. Hasil inventarisasi atau pemetaan dapat dalam bentuk tulisan foto maupun audio visual seperti video. Semua potensi dijadikan dokumen dan dapat dijual atau disajikan kepada wisatawan. Semua hasil inventarisasi dapat dijual atau dipasarkan dalam bentuk video, gambar yang dimuat dalam brosur, majalah, surat kabar dan juga internet.Pemasaran dapat dilakukan langsung pada daya tarik wisata dengan membentuk atau menggunakan kantor pemasaran. Penjualan produk tidak hanya dalam bentuk paket wisata trekking sebagai trigger . Namun juga dapat menjual hasil pertanian dilokasi trekking atau dipinggir jalan yang dapat dilihat oleh wisatawan dan masyarakat yang melintas di desa Belok Sidan. 
Peserta pelatihan baik dari peserta masyarakat (kepala desa, ketua kelompok sadar wisata dan ketua kelompok trekking "Titi Mamah"beserta anggota masyarakat yang juga sebagai anggota kelompok sadar wisata. Bapak kepada desa, ketua kelompok sadar wisata dan ketua kelompok trekking mengharapkan kegiatan pelatihan dapat dilakukan setiap tahun bahkan setiap enam bulan untuk memberikan penyegaran kepada kelompok sadar wisata dan kelompok trekking yang telah terbentuk sejak 10 tahun yang lalu. Potensi daya tarik wisata trekking telah menarik wisatawan mancanegara berkunjung dan menikmati kegiatan trekking seperti disajikan pada Gambar 3.1 yang berasal dari dokumentasi ketua kelompok trekking bapak I Made Darma. Kelompok trekking juga membuat pertanian organik dan hidroponik yang dipamerkan setiap tahun pada festival budaya pertanian di desa Petang tepatnya di lokasi Jembatan Bangkung, Pelaga, Petang, Badung.
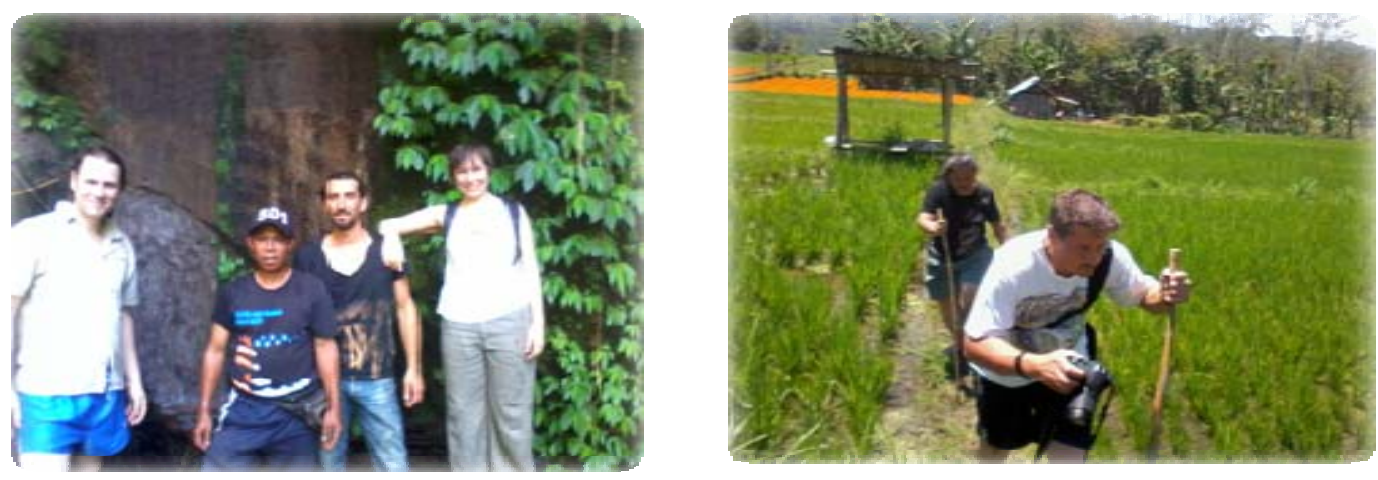

Gambar 3.1 Kegiatan Trekking yang dikelola Kelompok Trekking Titi Mamah, Belok Sidan

Menurut penuturan ketuan kelompok Trekking Titi Mamah I Made Darma, wisatawan yang membeli paket wisata trekkimg adalah wisatawan yang sedang menginap di Penginapan Bali Eco Village yang berlokasi di desa Belok Sidan. Wisatawan yang menggunakan jasa trekking tidak hanya wisatawan mancanegara seperti Italia, Jerman dan Belanda namun juga berasal dari Indonesaia, seperti Jakarta dan Surabaya. Paket trekking yang ditawarkan kelompok trekking Titi Mamah adalah paket trekking jarak jauh yang mencapai lokasi sampai ke kabupaten Bangli yang menggunakan jalur timur. Sedangkan jalur trekking ke dua adalah paket trekking kearah barat yang disebut dengan jalur pendek sampai ke wilayah Bedugul Tabanan. Kegiatan trekking juga dapat disesuikan dengan keinginan wisatawan, terutama wisatawan usia lanjut dan anak-anak, seperti kegiatan trekking menyusuri sungai dan sawah ladang.

Sejak dibentuknya kelompok sadar wisata, desa Belok Sidan dan ditetapkan sebagai Desa Wisata, kelompok ini aktif mengembangkan potensinya, terbukti dengan terbentuknya kelompok trekking "Titi Mamah". Desa Wisata Belok Sidan telah memasarkan produknya di pameran budaya pertanian yang diadakan setiap tahun di Jembatan Bangkung yang dilaksanakan oleh Pemerintah Kabupaten Badung.

\subsection{Pelatihan Teknik Pemanduan Wisata}

Setelah diberikan pelatihan manajemen daya tarik wisata, peserta selanjutnya diberikan pelatihan bagaimana teknik memandu wisata yang dapat memuaskan peserta trekking. Teknik pemanduan dimulai dari bagaimana tata cara menerima wisatawan (dimulai dengan greeting) dilanjutkan dengan menjelaskan produk yang dijual (paket yang telah ada atau jalur yang diinginkan oleh wisatawan). Pelatihan teknik pemanduan juga memberikan pengetahuan jalur dan waktu tempuh serta tempat yang akan dilalui dan temmpat stop over serta tempat berakhir. Pemandu juga 
diharapkan menjelaskan perlengkapan dan peralatan yang harus dibawa dan hal-hal yang tidak boleh dilakukan selama perjalanan trekking seperti merusak hutan dan membakar sesuatu yang dapat menimbulkan percikan api yang dapat menimbulkan kebakaran.

Pelatihan teknik pemanduan juga memberikan strategi memasarkan (menjual produk) yang berbasis kualitas layanaan dan kepuasan terhadap pelanggan. Setelah diberikan pelatihan teknik pemanduan, kelompok trekking langsung menjual produk trekkingnya dengan memberikan brosur dan kartu nama kepada pengunjung pameran budaya pertanian (lihat Gambar 3.2.2). Kelompok ini juga memasang banner selamat datang dan exbanner hasil kerjasama dengan program Studi Industri Perjalanan Wisata dalam bentuk pengabdian kepada masyarakat sebagai ketua pengabdian masyarakat tahun 2016 adalah Dr. I Nyoman Sudiarta,SE,M.Par beserta tim pengabdian Program Studi Industri Perjalanan Wisata, Program Studi Diploma 4 Pariwisata dan Program Studi Destinasi Pariwisata,Universitas Udayana. Dengan dilaksanakannya kegiatan pengabdian masyarakat, sekaligus menegaskan Desa Wisata Belok Sidan sebagai desa dampingan Program Studi Industri Perjalanan Wisata. Hal ini juga menegaskan bahwa Fakultas Pariwisata Universitas Udayana menjadi bagian yang tak terpisahkan dalam pengembangan potensi destinasi pariwisata dan daya tarik wisata di Bali, sekaligus membantu memasrkannya (Sudiarta dan Suardana, 2016; Sudana dan Mahadewi (2015); Sudiarta (2015).

\section{SIMPULAN DAN SARAN}

Secara umum dapat digambarkan bahwa kegiatan pelatihan manajemen daya tarik wisata di desa wisata Belok Sidan diikuti oleh peserta masyarakat; kelompok sadar wisata dan kelompok trekking Titi Mamah. Peserta mengikuti pelatihan sangat antusias dan mengharapkan pelatihan dilaksanakan secara berkelanjutan setiap tahun. Pelatihan pemanduan wisata juga telah dilaksanakan kepada peserta kelompok trekking dengan materi teknik pemanduan wisata. Peserta diberikan materi bagaimana cara pemanduan wisata mulai dari menyampaikan salam kepada wisatawan, menyampaikan lokasi dan waktu trekking, siapa pemandu yang akan menemani serta tempattempat istirahat dan waktu makan. Pelatihan ini juga menghasilkan produk berupa brosur, banner, exbanner dan kartu nama untuk memasarkan produk trekking Titi Mamah, desa Belok Sidan, Petang Badung.

Saran yang dapat disampaikan kepada kelompok sadar wisata dan kelompok trekking adalah agar kelompok ini lebih meningkatkan pengetahuan sumber daya manusianya baik pengetahuan tentang produk wisata, kemampuan bahasa asing dan kemampuan memasarkan produk yang dimiliki. Perlu melakukan inventarisasi kembali produk yang ada dan mendokumentasikan tidak hanya dalam bentuk foto namun juga dalam bentuk video.Memasarkan produk wisata trekking dalam bentuk promosi menggunakan media televise dan internet.

\section{UCAPAN TERIMAKASIH}

Penulis mengucapkan terima kasih yang tak terhingga kepada Rektor dan Ketua LPPM Universitas Udayana atas dana yang diberikan sehingga kegiatan pengabdian kepada masyarakat dapat dilaksanakan tepat waktu dan tepat sasaran. Terima kasih juga disampikan kepada Dekan Fakultas Pariwisata, Ketua Program Studi Industri Perjalanan Wisata dan anggota tim pengabdian serta nara sumber yang telah memberikan materi dan pengalaman kepada masyarakat desa Belok Sidan Petang Badung.. 


\section{DAFTAR PUSTAKA}

Foster, Dennis L (2000) First Class An Introduction To Travel \& Tourism, second edition Edisi bahasa Indonesia (terj Tri Budhi Sastrio), PT Raja Grafindo Persada. Jakarta.

Gee, ChuckY; Maken, James C; Choy, Dexter J.L (1997). The Travel Industry,Van Nostrand Reinhold.New York.

Sudiarta, I Nyoman dan Suardana, I Wayan (2016) Tourism destination planning strategy: analysis and implementation of marketing city tour in Bali. Procedia-Social and Behavioral Science. Vol. 227, pp. 664-670.

Sudiarta, I Nyoman (2015). Model Konseptual Destinasi Pariwisata dan Implikasi Penelitiannya dalam Paradigma dan Kebijakan Pariwisata, Cakra Press dan Fakutas Pariwisata Universitas Udayana. Denpasar

Sudana, I.P dan Eka Mahadewi, N.P. (2014) Pelatihan Mengkemas Paket Agrowisata Bagi Anggota Kelompok Tani Di Desa Kerta, Kecamatan Payangan, Kabupaten Gianyar, Vol. 14, No. 1, hal. 42-45.

Tjiptono, Fandy dan Chandra Gregorius (2011). Service, Quality \& Satisfaction, Andi. Yogyakarta. 